\title{
Analytically Directed Flavor Selection in Breeding Food Crops
}

\author{
Yan Wang1 and Stanley J. Kays ${ }^{2}$ \\ Department of Horticulture, The University of Georgia, Athens, GA 30602-7273
}

\begin{abstract}
ADDITIONAL INDEX wORDS. Ipomoea batatas, principal component analysis, sugars, nonvolatile acids, aroma-active compounds, flavor, quality

Abstract. Flavor quality is one of the most difficult traits to select in plant breeding programs due to the large number of sensory panelists required, the small number of samples that can be evaluated per day, and the subjectivity of the results. Using sweetpotato [Ipomoea batatas (L.) Lam.] as a model, clones exhibiting distinctly different flavors were analyzed for sugars, nonvolatile acids, and aroma chemistry to identify the critical flavor components. Differences in sugars, sucrose equivalents, nonvolatile acids, and 19 odor-active compounds were identified that accounted for differences in flavor among the clones. Using the intensity of the aroma per microliter for each of the 17 most important aroma-active compounds (maltol, 5-methyl-2-furfural, 2-acetyl furan, 3-furaldehyde, 2-furmethanol, benzaldehyde, phenylacetaldehyde, $\beta$-ionone, 1,2,4-trimethyl benzene, 2-pentyl furan, 2,4-decadienal, 2,4-nonadienal, linalool, geraniol, cyperene, $\alpha$-copane and a sesquiterpene) and the relative sweetness of individual sugars $\times$ their respective concentrations, multivariate (principal component and cluster) analysis allowed accurate classification of the clones according to flavor type without sensory analysis. The level of precision was such that sweetness, starch hydrolysis potential, and the concentration of $\beta$-carotene could be accurately predicted by quantifying specific volatiles. Analytical assessment of flavor would greatly facilitate the accurate evaluation of large numbers of progeny, the simultaneous selection of multiple flavor types, and the development of superior new cultivars for a wide cross-section of food crops.
\end{abstract}

For many food crops, flavor quality is one of the most difficult traits to assess in a breeding program. Flavor assessment is highly subjective and when done correctly, requires relatively large sensory panels that can test only a small number of samples per day. Superimposed on these deficits is the fact that the optimum flavor for a target population of consumers is seldom known. The net effect is that selection for flavor is generally relegated to one of the last traits assessed in a progeny selection sequence. Thus for many crops $>99 \%$ of the original progeny (and genetic variation) have been discarded before flavor assessment, essentially guaranteeing little or no improvement in flavor quality. Due to existing limitations on flavor assessment, most breeding programs rely to a large extent on the market place to determine if a new cultivar is sufficiently acceptable to consumers, an exceedingly inefficient means of addressing the problem. As a consequence, while new tomato (Lycopersicon esculentum Mill.) and strawberry (Fragaria $\times$ ananassa Duch.) cultivars tend to have large, attractive fruit that are slow to rot, their flavors almost invariably fall short of consumer expectations.

A more effective selection system would be to use an analytical measure of flavor that is amenable to screening large numbers of clones. Expanding the accuracy and number of progeny that can be assessed, allows moving selection for flavor earlier in the selection sequence, increasing the chances of finding truly superior clones. The development of an analytically directed selection system for flavor has three key requisites: 1 ) the flavor chemistry of the crop must be determined; 2) a rapid, accurate analytical method for measuring flavor must be developed; and 3) the chemistry of flavor preference of target populations of consumers must be determined.

In addition to increasing the speed and accuracy in which flavor can be improved, an analytically directed flavor selection system allows selecting for a wide cross-section of consumer groups simultaneously. For example, desirable flavor types of sweetpotatoes [Ipomoea batatas (L.) Lam.] in a breeding pro-

Received from publication on 23 Sept. 2002. Accepted for publication 8 Apr. 2003. 1Present address: FMC FoodTech, 1540 Linden Street, Riverside, CA 92507.

${ }^{2}$ To whom reprints should be addressed; e-mail kaysstan@uga.edu. gram in Peru could be selected for consumers in the highlands of Papua New Guinea and in Uganda at the same time without using sensory panels from either country. Once a small number of superior clones for a target population has been selected, the clones can then be tested using sensory panels made up of members of the targeted group.

To test the potential of developing an analytically directed flavor selection system, we chose the sweetpotato as a model for a number of reasons. The sweetpotato is one of the most important staple food crops in the world, ranking fifth in consumption in developing countries (Woolfe, 1992). Production per capita ranges from $193 \mathrm{~kg} \cdot \mathrm{year}^{-1}$ in the Solomon Islands to extremely small amounts in countries such as the United States (Food and Agr. Organization, 1997). Despite being highly nutritious (Kays and Kays, 1998), per capita consumption in the United States has declined tremendously since the early 1930s (Edmond and Ammerman, 1971). While $82.8 \%$ of U.S. households were identified as consumers of sweetpotato, only $10.4 \%$ purchased sweetpotatoes more than once a month (Law, 1977).

Flavor, composed of taste and aroma, is a primary component of sweetpotato quality associated with consumer preference (Tiu et al., 1985; Villareal et al., 1979) and there is tremendous genetic diversity in flavor present within the genepool of the crop (McLaurin and Kays, 1992). The taste perceived is strongly influenced by sugars, both present in the raw root (sucrose, fructose, and glucose) and formed via starch hydrolysis during cooking (maltose) (Kays and Wang, 2000). The contribution of volatile compounds, formed during cooking, to the aroma of sweetpotatoes has been the subject of several studies (Sun et al., 1995; Tiu et al., 1985; Wang and Kays, 2000; Wang and Kays, 2001).

When contrasted with other staple crops, the sweetpotato is relatively unusual in that the cooked product has a very distinct, dominant flavor. Most staples have low sugar contents (Villareal, 1982 ), e.g., rice $<1 \%$, wheat and white potato $\approx 2 \%$ versus $8 \%$ to $40 \%$ sugar in sweetpotato. The dominant flavor (taste and aroma) of the sweetpotato limits its culinary flexibility and thus the variety of distinctly different flavored dishes that can be prepared 
(Kays, 1985). Decreasing the flavor intensity of the sweetpotato has the potential to increase its acceptability as a staple food for human consumption.

This study was conducted to determine if sweetpotato clones can be separated into different flavor classes using pattern recognition analysis based upon quantification and weighting of key taste and aroma components.

\section{Materials and Methods}

Materials. 'Jewel' and 'Centennial' and four breeding lines (GA90-10, GA90-16, GA90-56 GA90-167) representing diverse flavor types were analyzed. The sweetpotatoes, grown at the University of Georgia Horticultural Farm in a Cecil sandy loam soil, were harvested, cured $\left(29^{\circ} \mathrm{C}, 95 \%\right.$ relative humidity for $\left.7 \mathrm{~d}\right)$ and stored at $15{ }^{\circ} \mathrm{C}, 85 \%$ relative humidity until analysis.

Preparation of BAKEd SAMPles FOR EVAluation OF SENSORY QUALITY. Three storage roots of each clone, selected for uniform size and shape, were individually wrapped in aluminum foil, placed in a convection oven and the temperature increased from 25 to $204{ }^{\circ} \mathrm{C}$ where they were held for a total baking time of 75 min. After removal from the oven, the roots were placed on a laboratory bench and allowed to cool for $\approx 5 \mathrm{~min}$ and then cut longitudinally and evaluated for sensory characteristics.

SEnSory EVAluation OF THE TASTe, AROMA, COLOR, AND TEXTURE. Sensory attributes of the baked samples were ascertained by two trained panelists. The samples were first characterized for aroma, then sweetness, texture, and color using descriptors developed by McLaurin and Kays (1992). The taste of cooked samples was determined and appropriate descriptors were assigned (e.g., white potato, North American sweetpotato, squash). The sweetness was assigned to one of four classes: sweet; slightly sweet; very slightly sweet; and nonsweet. The aroma was also determined and the appropriate descriptors assigned (e.g., cooked white potato aroma, cooked North American sweetpotato aroma, cooked squash aroma, starchy, etc.). The textural properties of cooked roots were subjectively categorized by mouth feel into the following classes: very moist, moist, medium dry, and dry. The following terms were used for individual flesh colors: cream, brown, gold, green, gray, orange, purple, tan, white, and yellow.

Color ANALYSES. The internal color of fresh root samples was measured using a tristimulus colorimeter (XL-20; Gardener Laboratory, Inc., Bethesda, Md.) calibrated against the white chromatic standard $(\mathrm{L}=92.0)$. Three cross-sectional 1-cm-thick slices were cut from about one-third of the way from each end and one from the center of three storage roots and measured within 2 min to minimize possible discoloration. Three measurements were taken from different areas on each slice to minimize the effect of uneven coloration. The final value was an average of 27 measurements per clone.

DRY MATTER, SUGAR, AND NONVOLATILE ACID ANALYSES. Three representative roots per clone were analyzed. To compensate for any variation in component distribution within the root, each root was cut longitudinally into quarters and each piece was further cut laterally. Two symmetrical pieces were peeled and cut into small, 3 to $5 \mathrm{~mm}$ cubes. Fifteen to $20 \mathrm{~g}$ of mixed cubes from the three roots per replication were combined, weighed, freeze-dried, reweighed, and stored at $-30^{\circ} \mathrm{C}$ until analysis. Three additional roots per clone were individually wrapped in aluminum foil, and placed in a convection oven. The temperature was increased from 25 to $204{ }^{\circ} \mathrm{C}$ and held there for a total baking time of $75 \mathrm{~min}$. A composite of 15 to $20 \mathrm{~g}$ of mixed cooked tissue from the three roots per replication was collected, freeze-dried, and stored at $-30{ }^{\circ} \mathrm{C}$ until analysis.

Freeze-dried raw and baked samples were finely grounded using a Cyclotec 1093 sample mill. One hundred mg of the flour was homogenized in $10 \mathrm{~mL} 80 \%$ methanol, containing $2.2 \mathrm{mg}$ phenyl- $\beta$-D-glucopyranose as an internal standard for $1 \mathrm{~min}$ at 15,000 rpm using a Handisher AC hand-held homogenizer. The resulting slurry was centrifuged for $5 \mathrm{~min}$ at $17,000 \mathrm{~g}_{n}$. Ten milliliters of supernatant was collected for analysis.

Oxime-trimethyl silyl (TMS) derivatization of sugars and TMS derivatization of nonvolatile acids were done according to Chapman and Horvat (1989) with slight modification. Sample extracts ( $50 \mu \mathrm{L}$ of raw, $25 \mu \mathrm{L}$ of baked) were pipetted into a vial, placed on a heating block at $40{ }^{\circ} \mathrm{C}$ and dried with a stream of nitrogen gas. Twenty-five microliters of hydroxylamine- $\mathrm{HCl}$ in pyridine $\left(25 \mathrm{mg} \cdot \mathrm{mL}^{-1}\right)$ was added to each vial and heated to 75 oC for $30 \mathrm{~min}$ for oximation. The oximes of sugars and the acids were then derivatized by adding $70 \mu \mathrm{L} \mathrm{N}, \mathrm{O}$-bis(trimethylsilyl) trifluoroacetamide (BSTFA) + 1\% trimethlychlorosilane (TMCS) per sample and heated at $75^{\circ} \mathrm{C}$ for $20 \mathrm{~min}$. After cooling, a $1 \mu \mathrm{L}$ injection was made into the gas chromatograph (GC) using an automatic HP $7673 \mathrm{GC} / \mathrm{SFC}$ injector and a HP 7673 controller (Hewlett-Packard, Wilmington, Del.). The oxime-TMS derivatives for the sugars and the TMS derivatives of the nonvolatile acids are stable for $20 \mathrm{hr}$ (Chapman and Horvat, 1989).

Gas chromatographic analyses were performed using a gas chromatograph (model 5890; Hewlett-Packard, Wilmington, Del.) equipped with a flame ionization detector (FID). The GC column was a $30 \mathrm{~m} \times 0.32 \mathrm{~mm}$ (i.d.) fused silica, DB-5, $0.25 \mu \mathrm{m}$ film thickness capillary column (J\&W Scientific, Folsom, Calif.). Samples were injected in the splitless mode. Injector and detector temperatures were 250 and $300^{\circ} \mathrm{C}$, respectively. Oven temperature was initially held at $150^{\circ} \mathrm{C}$ for $1 \mathrm{~min}$ and then programmed from 150 to $210^{\circ} \mathrm{C}$ at $4^{\circ} \mathrm{C} \cdot \mathrm{min}^{-1}$, held at $210^{\circ} \mathrm{C}$ for $0.5 \mathrm{~min}$, increased to $250^{\circ} \mathrm{C}$ at $7{ }^{\circ} \mathrm{C} \cdot \mathrm{min}^{-1}$, held at $250^{\circ} \mathrm{C}$ for $0.5 \mathrm{~min}$, and finally increased to $280^{\circ} \mathrm{C}$ at $4{ }^{\circ} \mathrm{C} \cdot \mathrm{min}^{-1}$ and held for $5 \mathrm{~min}$. Helium was used for the carrier gas at a flow rate of $53.1 \mathrm{~mL} \cdot \mathrm{min}^{-1}$. Air and hydrogen flow rates to the detector were 370 to $380 \mathrm{~mL} \cdot \mathrm{min}^{-1}$ and $28 \mathrm{~mL} \cdot \mathrm{min}^{-1}$, respectively. Nitrogen was used as the makeup gas at a flow rate of $30 \mathrm{~mL} \cdot \mathrm{min}^{-1}$. An HP3392A integrator was connected to the GC for peak area measurement.

Identifications of sugars and acids were based on retention times using authentic standards and by adding standards to samples before extraction to verify retention times. Fructose yielded two peaks ( $\alpha$ and $\beta$ isomers) in a 1:1 ratio that were summed for quantification. A mixture containing known amounts of the internal standard (phenyl- $\beta$-D-glucopyranose) and reference sugars and acids (fructose, galactose, glucose, inositol, sucrose, and maltose and malic acid, citric acid, quinic acid, and succinic acid) was analyzed to obtain correction factors. Sugars and acids were quantified using internal standard methodology and expressed as weight percent of dry matter. Recovery tests were carried out using standard additions with sucrose in the raw and maltose in the baked samples. About $97 \%$ and $95 \%$ recoveries were achieved for sucrose and maltose and as a consequence, the technique was considered to be quantitative. Since individual sugars vary in their sweetness, to obtain a composite measure of sweetness for comparisons among lines, sucrose equivalents were calculated using a previously determined equation: sucrose equivalent $=$ 1.2 fructose +1 sucrose +0.64 glucose +0.43 maltose (Koehler and Kays, 1991). Galactose and inositol were not included due to their low sweetness and/or levels in the clones. 
VOLATILE COLLECTION, GC, GC-MS, AND GC-OLFACTORY ANALYSES. Five representative roots ( 7 to $9 \mathrm{~cm}$ in diameter) of each clone were washed and peeled. Cross-sectional cores $(1.7 \mathrm{~cm}$ i.d.) were removed, giving samples of each clone with equivalent fresh weights $(350 \mathrm{~g})$ and approximately equivalent surface areas. The root cores for each clone were wrapped in aluminum foil, placed in an electric convection oven and the temperature increased from 25 to $204{ }^{\circ} \mathrm{C}$ where it was held for a total baking time of $70 \mathrm{~min}$. Volatiles were immediately collected from the baked cores by placing them inside a specially constructed 1 -L glass container for 70 min at $50^{\circ} \mathrm{C}$. GC, GC-MS, and GCO analyses were conducted as described previously (Wang and Kays, 2000).

DATA ANALYSIS. All data were subjected to a one-way analysis of variance (ANOVA). Significant differences between clones were compared using Duncan's multiple range test.

Data transformation for statistical comparisons among clones were made by weighting each component (volatile and sugar) based upon its relative impact on aroma or sweetness.

Weights for volatiles were based on flavor dilution (FD) values created by an aroma extract dilution analysis (AEDA) (Grosch, 1993) of each volatile (Wang and Kays, 2000). A series of increasingly dilute solutions of the aroma extract were analyzed by GCO evaluation. The FD value is the last dilution at which an odor-active compound was detected by at least two of the three panelists. The dilution series $(10 \%, 1 \%, 0.5 \%, 0.25 \%, 0.125 \%$, $0.1 \%, 0.065 \%, 0.05 \%$, and $0.025 \%$ ) was prepared from the original volatile extract and the correspondent FD values were 10, 100, 200, 400, 800, 1000, 1500, 2000, and 4000 (Wang and Kays, 2000). The FD value for each volatile was divided by its respective concentration to give a relative potency per microliter. These values were then multiplied by the concentration of the volatile in the aroma of each clone to give the weighted value for analysis. For individual sugars, the concentration of each was multiplied by its relative sweetness. Weighted volatile and sugar data were used in subsequent principal component and cluster analyses.

Multivariate analysis was used for data interpretation of the volatile compounds. The volatile data were subjected to principal component analysis (PCA) to determine which parameters contributed most to differences among cultivars. Cluster analysis (CA) was used to classify the clones based on aroma. All statistical tests were conducted using SAS (SAS Institute Inc, Cary, N.C.).

\section{Results and Discussion}

The sensory qualities of the six clones are summarized in Table 1. The clones exhibited a broad range in aroma, taste, sweetness and other sensory quality attributes and provided the genetic diversity needed to begin to identify and assess the impact of specific compounds on the flavor of the sweetpotato.

Sugars AND NONvolatile ACIDS. The flavor quality of sweetpotatoes in the United States is strongly modulated by sweetness and as a consequence, quantitative and qualitative variation in sugars is of critical importance. There is a tremendous range in sweetness within the sweetpotato genepool (McLaurin and Kays, 1992) with the sweetness of the cooked product being a function of the initial sugar concentration in the raw product and that formed via starch hydrolysis during cooking (Morrison et al., 1993). The importance of organic acids in the flavor has not been established although an apparent range in organic acids has been noted in germplasm collections based on sensory analysis. The clones in this study were not selected for a significant range in organic acids. The major organic acids and sugars were identified as malic acid, citric acid, quinic acid, fructose, galactose, glucose, inositol, sucrose, and maltose in order of elution from the GC. There were no qualitative differences among clones nor between raw and baked samples with the exception that the raw roots had negligible amounts of maltose which is formed during cooking. Quantitatively, the sugars and nonvolatile acids and dry matter differed significantly among the clones in raw roots (ANOVA $p$ $=0.01$ ) (Table 2). Moreover, baking often significantly affected the level of these compounds (Table 3). The concentration of maltose was highest in GA90-56 (29.08 g/100 g dry matter) and lowest in GA90-16 (0.17 g/100 g dry matter). 'Centennial' had the highest level of sucrose (26.25 g/100 g dry matter) and GA9016 the lowest $(5.67 \mathrm{~g} / 100 \mathrm{~g}$ dry matter). Fructose and glucose concentrations were highest in 'Jewel' (6.75 and $8.14 \mathrm{~g} / 100 \mathrm{~g}$ dry matter, respectively) and lowest in 'Centennial' (0.44 and 0.65 $\mathrm{g} / 100 \mathrm{~g}$ dry matter) and GA90-10 (0.51 and $0.77 \mathrm{~g} / 100 \mathrm{~g}$ dry

Table 1 . Sensory qualities of the six sweetpotato clones.

\begin{tabular}{llllll}
\hline Clone & Aroma & Taste & Sweetness & Color & Texture \\
\hline Jewel & Cooked North American sweetpotato & Sweet North American sweetpotato & Sweet & Orange & Very moist \\
Centennial & North American sweetpotato & Sweet North American sweetpotato & Sweet & Orange/gold & Moist \\
GA90-10 & Strong terpene odor & Baked potato & Nonsweet & Gold/yellow & Moist \\
GA90-16 & Potato $^{z}$ & Baked potato & Nonsweet & Cream & Medium dry \\
GA90-56 & Cooked squash, musty & Squash sweet & Sweet & Gold & Moist \\
GA90-167 & Musty, starchy & Potato & Slightly sweet & Cream/yellow & Dry \\
\hline
\end{tabular}

zThe term potato denotes Solanum tuberosum L.

Table 2. Sugar and nonvolatile acid contents ( $\mathrm{g} / 100 \mathrm{~g}$ dry matter) of baked roots of six sweetpotato clones.

\begin{tabular}{|c|c|c|c|c|c|c|c|c|c|c|c|}
\hline Clone & Malic & Citric & Quinic & Fructose & Galactose & Glucose & Inositol & Sucrose & Maltose & $\begin{array}{l}\text { Sucrose } \\
\text { equivalentz }\end{array}$ & $\mathrm{DM}^{y}$ \\
\hline Centennial & $1.37 \mathrm{ab}$ & $0.07 \mathrm{bc}$ & $0.42 \mathrm{~b}$ & $0.44 \mathrm{e}$ & $0.04 \mathrm{~b}$ & $0.65 \mathrm{~d}$ & $0.31 \mathrm{a}$ & $26.25 \mathrm{a}$ & $25.44 b$ & $38.13 \mathrm{~b}$ & $30.14 \mathrm{c}$ \\
\hline GA90-16 & $0.48 \mathrm{~b}$ & $0.05 \mathrm{c}$ & $0.40 \mathrm{~b}$ & $2.04 \mathrm{c}$ & $0.06 \mathrm{~b}$ & $2.88 \mathrm{c}$ & $0.06 \mathrm{c}$ & $5.67 \mathrm{f}$ & $0.17 \mathrm{e}$ & $10.02 \mathrm{e}$ & $34.79 \mathrm{~b}$ \\
\hline GA90-56 & $1.91 \mathrm{a}$ & $0.26 \mathrm{~b}$ & $0.72 \mathrm{a}$ & $4.48 \mathrm{~b}$ & $0.07 \mathrm{~b}$ & $5.47 \mathrm{~b}$ & $0.29 \mathrm{a}$ & $21.98 \mathrm{~b}$ & $29.08 \mathrm{a}$ & $43.37 \mathrm{a}$ & $21.64 \mathrm{e}$ \\
\hline GA90-167 & $0.79 \mathrm{~b}$ & $0.08 \mathrm{bc}$ & $0.68 \mathrm{a}$ & $1.51 \mathrm{~d}$ & $0.03 \mathrm{~b}$ & $1.62 \mathrm{~d}$ & $0.20 \mathrm{ab}$ & $10.88 \mathrm{~d}$ & $12.95 \mathrm{c}$ & $19.30 \mathrm{c}$ & $34.54 \mathrm{~b}$ \\
\hline
\end{tabular}

Per $100 \mathrm{~g}$.

${ }^{\mathrm{y}} \mathrm{DM}=$ dry matter percent.

xMean separation within columns by Duncan's multiple range test, $p=0.05$. 
Table 3. Sugar and nonvolatile acid contents ( $\mathrm{g} / 100 \mathrm{~g}$ dry matter) in baked and raw roots of six sweetpotato clones.

\begin{tabular}{llccccccccc}
\hline Clone & Treatment & Malic & Citric & Quinic & Fructose & Galactose & Glucose & Inositol & Sucrose & Maltose \\
\hline Jewel & Raw & 1.59 & 0.41 & 0.37 & 5.50 & 0.13 & 6.31 & 0.15 & 18.80 \\
& Baked & 2.01 & 0.49 & 0.44 & 6.75 & 0.18 & 8.14 & 0.16 & 20.19 & 24.42 \\
& Significance & $* * *$ & NS & NS & $* * *$ & NS & $* *$ & NS & $* *$ & $* * *$ \\
Centennial & Raw & 1.29 & 0.04 & 0.27 & 0.25 & 0.03 & 0.31 & 0.22 & 19.53 & 0 \\
& Baked & 1.37 & 0.07 & 0.42 & 0.44 & 0.04 & 0.65 & 0.31 & 26.25 & 25.44 \\
& Significant & NS & NS & NS & $* * *$ & NS & $* *$ & NS & $* * *$ & $* * *$ \\
GA90-10 & Raw & 0.86 & 0.17 & 0.40 & 0.57 & 0.02 & 0.78 & 0.14 & 7.89 & 0.01 \\
& Baked & 0.91 & 0.15 & 0.51 & 0.51 & 0 & 0.77 & 0.15 & 8.79 & 5.18 \\
& Significance & NS & NS & NS & NS & NS & NS & NS & $* *$ \\
GA90-16 & Raw & 0.39 & 0.09 & 0.24 & 1.47 & 0.08 & 2.02 & 0.09 & 5.61 & 0.02 \\
& Baked & 0.40 & 0.05 & 0.40 & 2.04 & 0.06 & 2.88 & 0.06 & 5.67 & 0.17 \\
& Significance & NS & NS & NS & $*$ & NS & $* *$ & NS & NS & $* *$ \\
GA90-56 & Raw & 1.55 & 0.25 & 0.62 & 4.06 & 0.11 & 4.43 & 0.26 & 21.34 & 0.03 \\
& Baked & 1.91 & 0.26 & 0.72 & 4.48 & 0.07 & 5.47 & 0.29 & 21.98 & 29.08 \\
& Significance & $*$ & NS & NS & $* * *$ & NS & $* *$ & NS & $* *$ \\
GA90-167 & Raw & 0.51 & 0.07 & 0.35 & 1.09 & 0.05 & 1.39 & 0.16 & 10.39 & 0.01 \\
& Baked & 0.79 & 0.08 & 0.68 & 1.51 & 0.03 & 1.62 & 0.20 & 10.88 & 12.95 \\
& Significance & $*$ & NS & $* * *$ & $*$ & NS & $* * *$ & NS & NS & $* * *$ \\
\hline
\end{tabular}

ss,***,****Nonsignificant or significant at $p=0.10,0.05$, or 0.01 , respectively, by $t$ test.

matter). There were no significant differences for fructose and glucose between 'Centennial' and GA90-10. Lewthwaite et al. (1997) reported that the glucose content was higher than that of fructose and the ratio was relatively stable across nine cultivars. A similar relationship was found for the clones in the current study. Malic acid was the predominant acid and was highest in 'Jewel' (2.01 g/100 g dry matter) and lowest in GA90-16 (0.48 $\mathrm{g} / 100 \mathrm{~g}$ dry matter).

The perception of sweetness by humans varies among different sugars (Shallenberger, 1993). As a consequence, expressing the sweetness of individual sugars relative to sucrose allows a more accurate assessment of their impact on flavor (Koehler and Kays, 1991). Sucrose equivalents (SE) is the summation of the concentration corrected for relative sweetness of the sugars present. GA90-10 and GA90-16 were considered nonsweet by panelists and had sucrose equivalents of 12.1 and 10.0 (based on g/100 g dry matter) and dry matter contents of $37.0 \%$ and $34.8 \%$ (Table 2 ), respectively. GA90-167 was slightly sweet and had an SE of 19.3 and dry matter of $34.5 \%$. GA90-56, 'Jewel' and 'Centennial', which were all sweet, had sucrose equivalents of 43.4, 44.0, 38.1, and 21.6, 23.9, 30.1/100 g dry matter, respectively.

There was a significant change in total sugars in all clones with cooking due to the production of maltose with the exception of GA90-16 in which maltose synthesis is inhibited (Table 3). Alpha- and beta-amylase are able to attack gelatinized starch (gelatinization occurs at 68 to $73^{\circ} \mathrm{C}$ when adequate moisture is present) and are responsible for maltose formation (Walter et al., 1976). Alpha-amylase hydrolyzes starch via an endo process into amyloid polymers called dextrins (Walter et al., 1975), while betaamylase hydrolyzes both starch and dextrins to maltose (Morrison et al., 1993; Walter et al., 1975). The formation of maltose and therefore its contribution to the sweetness of the cooked product, is highly clone dependent. GA90-16 produced only negligible amounts of maltose during cooking indicating an inhibition of the $\beta$-amylase system. Changes in sucrose, fructose and glucose (present in the raw product) during cooking, reported in the literature, vary. Several studies have found the concentrations of fructose, glucose, and sucrose to increase upon cooking (Picha, 1985; Takahata et al., 1992), while others found a reduction or essentially no change (Morrison et al., 1993; Sun et al., 1994).
We found the changes in endogenous sugars and nonvolatile acids with cooking to be clone dependent (Table 3). For example, the concentrations of malic acid, fructose, glucose and sucrose in 'Jewel' increased significantly but there was little change in GA90-10 (with the exception of sucrose) and GA90-16 (with the exception of glucose) upon cooking.

While sucrose equivalents provide an excellent indicator of the relative sweetness of individual clones, it has one deficiency in that it does not take into consideration differences in taste quality among sugars. Sweetpotato sensory panelists ranked three of the constituent sugars in the following order of preference: maltose $>$ sucrose $>$ fructose (Koehler and Kays, 1991). As a consequence, selection criteria in sweetpotato breeding programs should use both sucrose equivalents and the levels of specific sugars. This is particularly important in processed sweetpotato products such as chips and french fries since reducing sugars can result in undesirable browning (Picha, 1986). Clones such as GA90-16 that have very low levels of reducing sugars would have distinct advantages for certain processed products.

COLOR ChaRACTERISTICS. Carotenoids, predominately $\beta$-carotene, are responsible for the yellow to orange coloration of the roots. While the carotenoids do not appear to contribute appreciably to the flavor directly, sensory panelists tended to describe the flavor of deeply orange clones as pumpkin- or carrot-like (McLaurin and Kays, 1992). The primary effect of the carotenoids on the flavor

Table 4. Mean $(\mathrm{n}=27)$ raw root color values $($ Hunter $\mathrm{L})$ and estimated $\beta$-carotene content $[\mathrm{B}=(\mathrm{L}-75.18145) /(-4.05) ; \mathrm{r}=0.81]$ of six sweetpotato clones.

\begin{tabular}{lcc}
\hline Clone & $\mathrm{L}$ & $\begin{array}{c}\text { Estimated } \\
\beta \text {-carotene } \\
(\mathrm{mg} / 100 \mathrm{~g} \text { fresh wt })\end{array}$ \\
\hline Centennial & $55.6 \mathrm{e}^{\mathrm{z}}$ & 4.84 \\
Jewel & $60.8 \mathrm{~d}$ & 3.55 \\
GA90-56 & $66.6 \mathrm{~cd}$ & 2.13 \\
GA90-167 & $70.9 \mathrm{bc}$ & 1.05 \\
GA90-16 & $72.9 \mathrm{~b}$ & 0.57 \\
GA90-10 & $78.1 \mathrm{a}$ & 0.00
\end{tabular}

"Mean separation within column by Duncan's multiple range test, $p=$ 0.05 . 


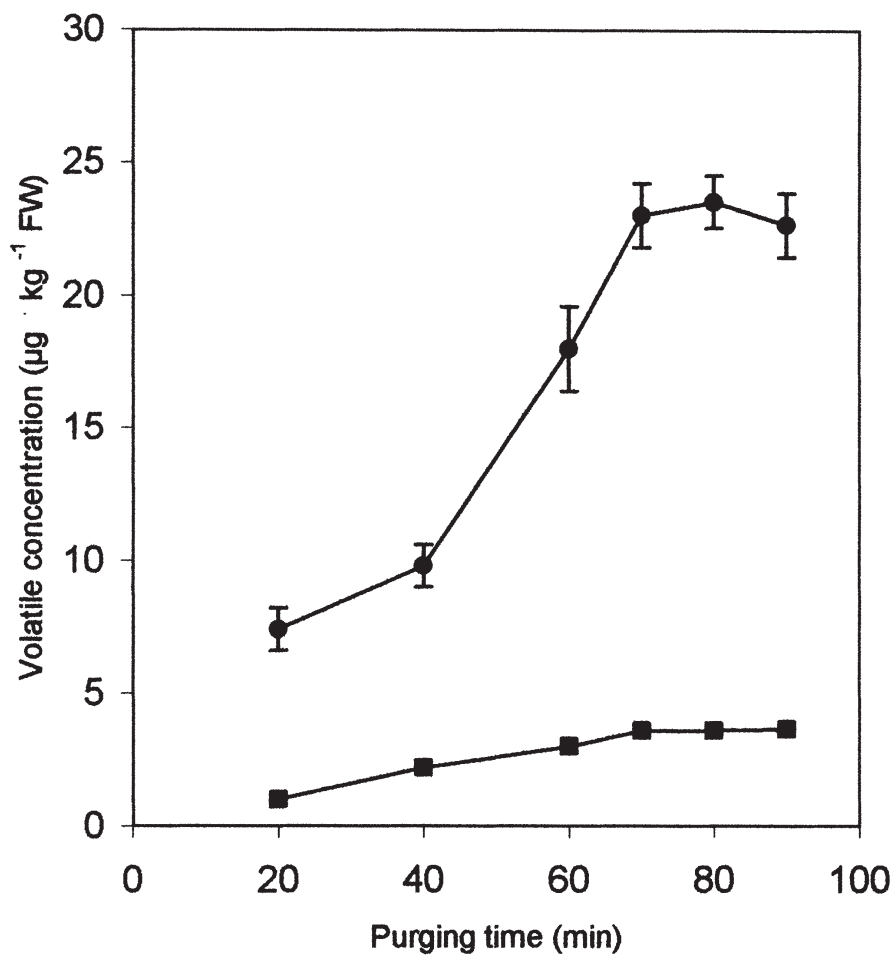

Fig. 1. Effect of collection time on the relative amount of odor-active compounds (O) and maltol (ם) (350 g baked sweetpotato root cores placed inside a 1-L container, helium carrier gas flow rate at $35 \mathrm{~mL} \cdot \mathrm{min}^{-1}$, and at temperature of $\left.50^{\circ} \mathrm{C}\right)$. Vertical bars represent one standard deviation. appears to be due to compounds derived from their degradation during cooking (Wang and Kays, 2000). A linear relationship has been reported between Gardener L values and $\beta$-carotene contents for a cross-section of clones $(r=0.81)$ (Simonne et al., 1993). The predicted $\beta$-carotene contents based on the $L$ values for the clones in this study are presented in Table 4; values for 'Centennial', 'Jewel', and GA90-10 had been previously documented (Simonne et al., 1993). The L values for GA90-10 were similar between this study and the previous, while L values were slightly lower (i.e., darker) for 'Jewel' (60.8 vs 65.3) and 'Centennial' (55.6 vs 66.2). Using the prediction equation of Simonne et al. (1993), the $\beta$-carotene contents of the clones in this study were calculated from their L values and ranged from 0 (GA90-10) to $4.84 \mathrm{mg} / 100 \mathrm{~g}$ fresh weight ('Centennial'). Sweetpotato breeders in the United States have focused on increasing the $\beta$-carotene content in new cultivars in that it is the primary provitamin A carotenoid. Progressive up-regulation of the terpene biosynthetic pathway for increased carotenoids, however, has resulted in a concurrent alteration in flavor chemistry that for many consumers is undesirable. High carotene breeding lines are commonly described as strongly pumpkin- or carrot-like in flavor, giving the selection an even more pronounced and distinctive overall flavor than most low carotene lines (McLaurin and Kays, 1992). The prevailing approach in selection for increased carotenoids has in general been the more, the better. There are, however, distinct qualitative trade-offs with this approach.

IMPORTANT ODOR-ACTIVE VOLATILES. To compare the critical odor compounds quantitatively, the optimum collection time was determined for the composite of 19 odor-active compounds. The

Table 5. Relative weighting factors and concentrations ( $\mu \mathrm{g} \cdot \mathrm{kg}^{-1}$ fresh weight) of the critical aroma compounds in six baked sweetpotato clones.

\begin{tabular}{|c|c|c|c|c|c|c|c|}
\hline Compound & Relative weighting factor ${ }^{Z}$ & Jewel & Centennial & GA90-10 & GA90-16 & GA90-56 & GA90-167 \\
\hline \multicolumn{8}{|l|}{ Maillard/caramelization } \\
\hline 5-Methyl-2-furfural & 444.4 & $0.22 \mathrm{c}$ & $0.47 \mathrm{a}$ & $---x$ & $0.04 \mathrm{c}$ & $0.18 \mathrm{~d}$ & $0.39 \mathrm{~b}$ \\
\hline 3-Furaldehyde & 0.7 & $3.91 \mathrm{~b}$ & $4.78 \mathrm{a}$ & $0.24 \mathrm{e}$ & $1.40 \mathrm{~d}$ & $5.11 \mathrm{a}$ & $2.63 \mathrm{c}$ \\
\hline 2-Furmethanol & 7.1 & $3.79 \mathrm{a}$ & $3.80 \mathrm{a}$ & $1.23 \mathrm{~d}$ & $1.20 \mathrm{~d}$ & $3.26 \mathrm{~b}$ & $2.77 \mathrm{c}$ \\
\hline \multicolumn{8}{|l|}{ Strecker Degradation Products } \\
\hline \multicolumn{8}{|c|}{ Degradation Products of $\beta$-carotene } \\
\hline$\beta$-Ionone & 625.0 & $0.88 \mathrm{a}$ & $0.89 a$ & --- & $0.03 \mathrm{~d}$ & $0.45 b$ & $0.32 \mathrm{c}$ \\
\hline 1,2,4-Trimethyl benzene & 296.0 & $0.69 \mathrm{a}$ & $0.89 \mathrm{a}$ & $\operatorname{Tr}$ & $0.22 \mathrm{~d}$ & $0.53 \mathrm{~b}$ & $0.33 \mathrm{c}$ \\
\hline \multicolumn{8}{|l|}{ Degradation Products of Lipids } \\
\hline 2-Pentyl furan & 833.3 & $0.32 \mathrm{a}$ & $0.39 \mathrm{a}$ & --- & $0.13 \mathrm{~b}$ & $\operatorname{Tr}$ & $\operatorname{Tr}$ \\
\hline Linalool & 1000.0 & $0.24 \mathrm{~b}$ & $0.35 \mathrm{a}$ & $\operatorname{Tr}$ & $0.07 \mathrm{~d}$ & $0.15 \mathrm{c}$ & $0.08 \mathrm{~d}$ \\
\hline Geraniol & 2500.0 & $0.13 \mathrm{a}$ & $0.13 \mathrm{a}$ & $\operatorname{Tr}$ & $0.13 \mathrm{a}$ & $0.08 \mathrm{ab}$ & $0.06 \mathrm{~b}$ \\
\hline Methyl geranate & $\operatorname{Tr}$ & $\operatorname{Tr}$ & $\operatorname{Tr}$ & $\operatorname{Tr}$ & $\operatorname{Tr}$ & $\operatorname{Tr}$ & $\operatorname{Tr}$ \\
\hline Cyperene & 1.0 & --- & --- & $2.34 \mathrm{a}$ & $1.02 \mathrm{~b}$ & $0.60 \mathrm{c}$ & $0.15 \mathrm{~d}$ \\
\hline$\alpha$-Copaene & 2666.7 & $0.32 \mathrm{~b}$ & $0.22 \mathrm{c}$ & $1.42 \mathrm{a}$ & $0.21 \mathrm{c}$ & $0.15 \mathrm{~d}$ & $0.11 \mathrm{e}$ \\
\hline Sesquiterpene (MW204) & 100.0 & --- & --- & $2.32 \mathrm{a}$ & $0.17 \mathrm{~b}$ & $0.34 \mathrm{~b}$ & $0.17 \mathrm{~b}$ \\
\hline
\end{tabular}

ZRelative weighting factor = flavor dilution factor/concentration from cultivar 'Jewel' (Wang and Kays, 2000).

YMean separation of the concentrations within rows by Duncan's multiple range test, $p=0.05$.

xNot detected by either GC or olfactory analysis.

w $\operatorname{Tr}=<1 \%$ Based on GC peak areas. 


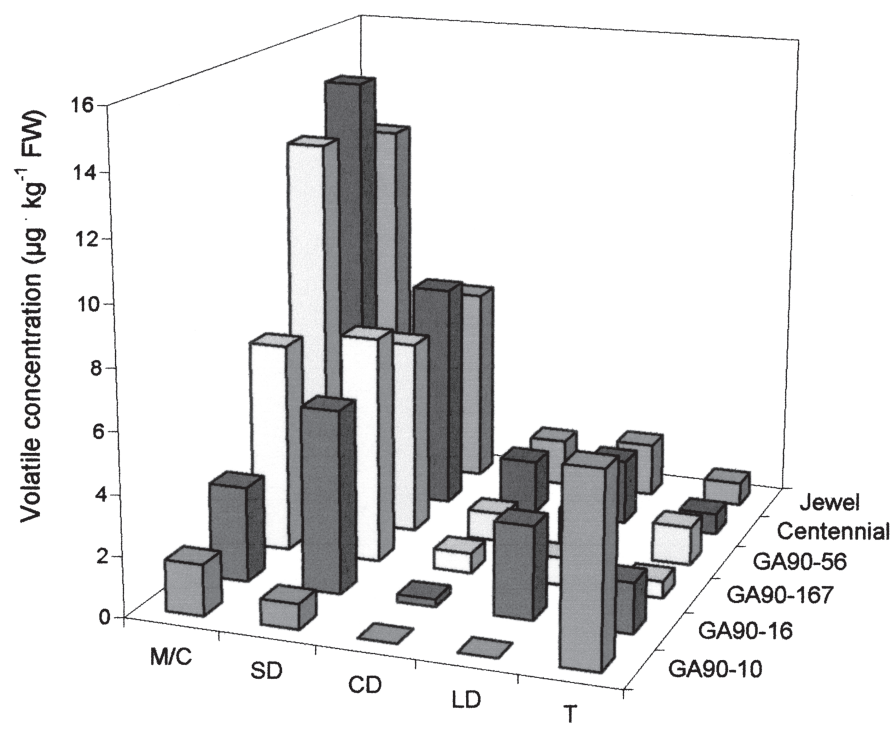

Fig. 2. Variation in the synthesis of aroma-active compounds from six baked sweetpotato clones. Aroma-active compounds are grouped by origin, Maillard/caramelization products (M/C), Strecker degradation products (SD), $\beta$-carotene degradation products (CD), lipid derived compounds (LD) and terpenoids (T).

composite over time of the odor-active compounds and one representative compound (maltol) from 'Jewel' are shown in Fig. 1. Changes in maltol were typical of that observed for the majority of the compounds and as a consequence, a 70 min collection time at a $35 \mathrm{~mL} \cdot \mathrm{min}^{-1}$ helium flow rate was used.

GC-olfactory analyses indicated that 26 distinct odors could be detected at the GC exit port for the clones. The intensity of some odors varied among genotypes, ranging from absent to strong (data not shown). Several quantitatively significant compounds contributed little or nothing to the overall aroma at the concen-

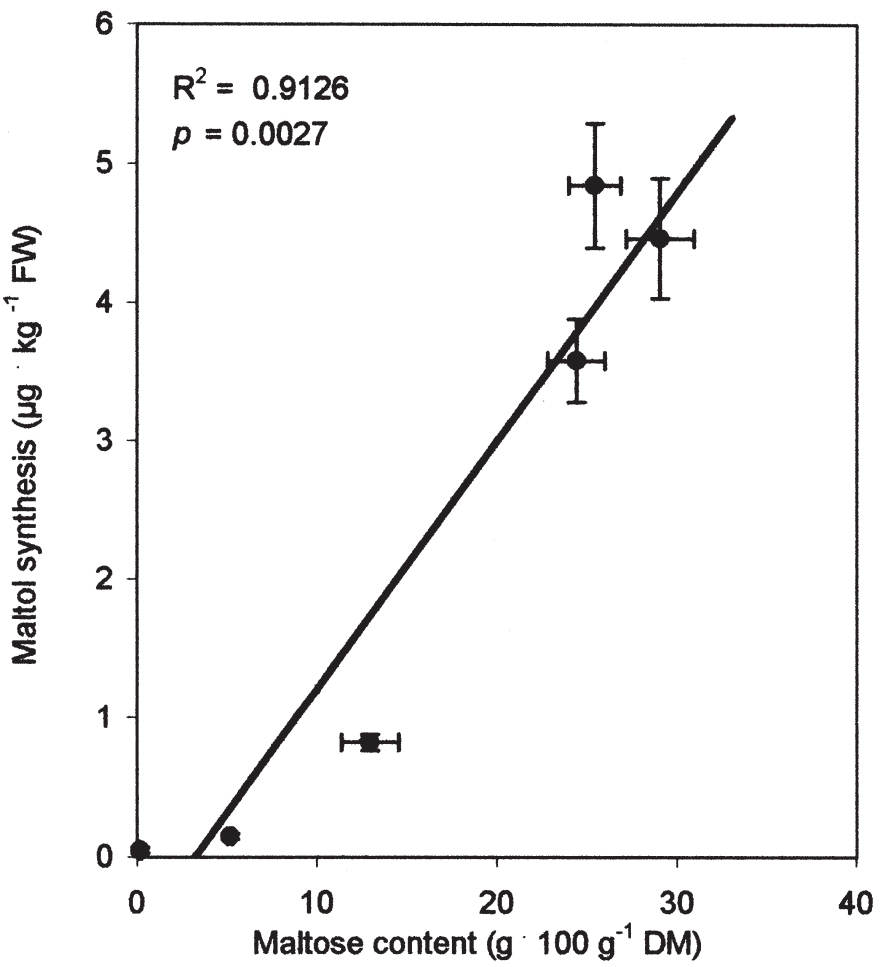

Fig. 3. The relationship between maltose content and volatile maltol production across six baked sweetpotato clones. Vertical and horizontal bars represent one standard deviation. trations encountered (e.g., palmitic acid). The concentrations of the 19 most important aroma contributors were determined (Table 5) using internal standard methodology [i.e., peak area to internal standard (ethyl benzoate) ratio related to sample weight]. The results revealed distinct quantitative, and to a lesser extent, qualitative differences in the 19 aroma-active compounds among the clones. Figure 2 illustrates the variation among clones in aroma-active volatile compounds grouped by their molecular origin (i.e., Maillard/caramelization reaction products, Strecker degradation products, lipid derived products, $\beta$-carotene derived products, and terpenoids).

Maillard/caramelization reaction volatiles primarily contributed caramel and sweet aroma properties (Wang and Kays, 2000). With the exception of the absence of 5-methyl-2-furfural in GA90-10, all other Maillard/caramelization reaction products were detected in each of the clones. There were, however, substantial quantitative differences in volatiles among clones that appear to be responsible for the various aromas. The yield of Maillard/caramelization reaction products was positively correlated to clone sweetness (i.e., 'Jewel', 'Centennial', and GA90-56 had higher sugar contents and produced higher levels of Maillard/caramelization volatiles). Maltol, with its sweet caramel aroma, has been shown to be one of the most important contributors to the aroma of baked 'Jewel' sweetpotatoes (Wang and Kays, 2000). Sugars are precursors of Maillard/caramelization reaction volatile compounds; for example, maltose is an efficient precursor of maltol (Sun et al., 1993). Across clones there was a positive relationship between maltose content and maltol formation $\left(R^{2}=0.91, p=0.0027\right)$ (Fig. 3). The possibility of using Maillard/caramelization derived volatile compounds to predict sucrose equivalents was tested by simple and stepwise multiple linear regression analysis. The model $\mathrm{Y}=\beta_{0}+\beta_{1}\left(\mathrm{X}_{1}+\right.$ $\left.\mathrm{X}_{2}+\mathrm{X}_{3}\right)$ had the lowest $p$ value $(0.0024)$ and an $R^{2}$ of $0.92\left(\mathrm{X}_{1}\right.$ $=$ maltol, $X_{2}=3$-furaldehyde and $X_{3}=2$-furmethanol) (Fig. 4). The parameter $\beta_{0}=4.66$ and parameter $\beta_{1}=2.89$.

Beta-ionone and 1,2,4-trimethyl benzene, thermal degradation products of $\beta$-carotene (Kanasawud and Crouzet, 1990), are produced in high amounts in the orange flesh color cultivar 'Jewel' (Wang and Kays, 2000), imparting strong floral and violet aromas, respectively. A significant positive relationship was found between the estimated $\beta$-carotene contents of the clones $\left(R^{2}=0.98, p=0.0001\right)$ and the production of $\beta$-ionone and 1,2,4trimethyl benzene (Fig. 5).

Compounds derived from fatty acids (e.g., 2-pentyl furan, 2,4-nonadienal, 2,4-decadienal, and n-decanal) showed distinct qualitative and quantitative variation among clones (Table 5). GA90-10, however, was devoid of these compounds. A higher concentration of 2,4-decadienal, reported to be an important aroma compound in baked potato (Buttery et al., 1973) and cooked rice (Grosch and Schieberle, 1997), was produced in GA90-16 than in the other clones. The cooked potato-like aroma of GA90-16 appears to come mainly from the contribution of 2-acetyl furan and 2,4-decadienal, which contribute baked potato and cooked starch aromas, respectively (Wang and Kays, 2000). While the 2-acetyl furan content in GA90-16 was equal to 'Jewel' (0.59 vs $0.58 \mu \mathrm{g} / 100 \mathrm{~g}$ fresh weight), the substantially higher level of sweet caramel odors in 'Jewel' from maltol and other compounds tended to mask its aroma.

Two monoterpene alcohols (linalool and geraniol), one monoterpene ester (methyl geranate), and three sesquiterpenes (cyperene, $\alpha$-copaene and an unidentified compound with a molecular weight of 204) exhibited qualitative and quantitative differences 


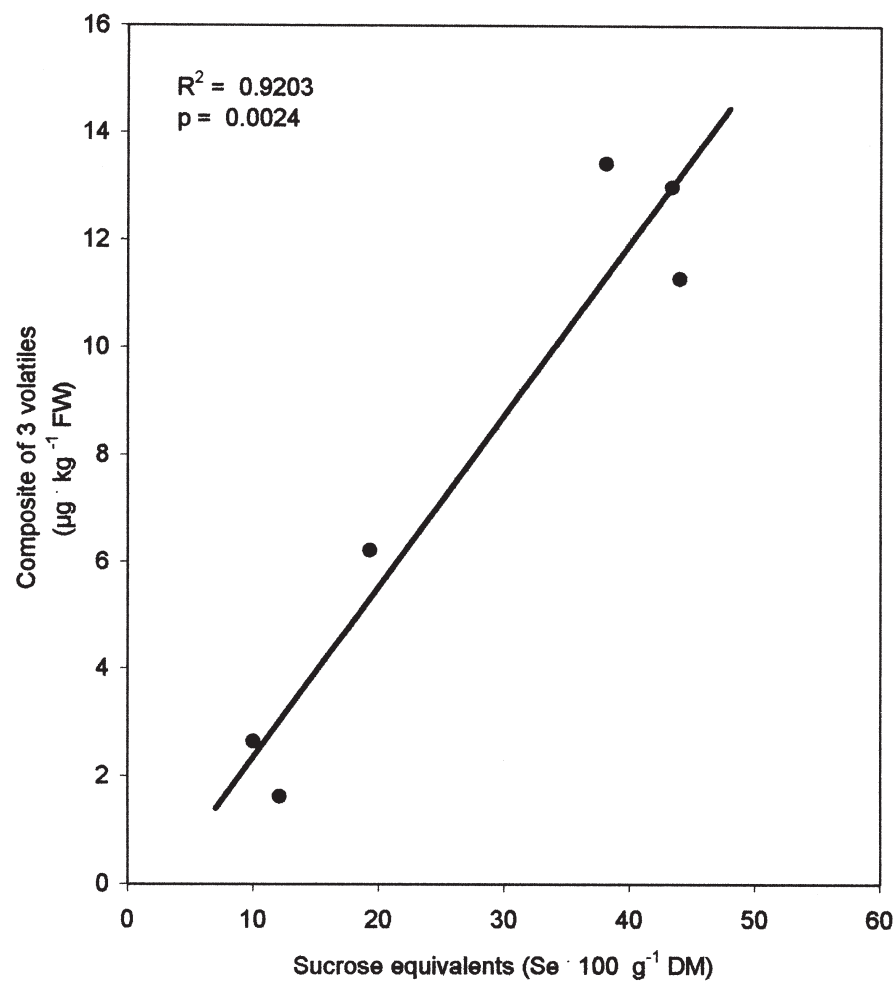

Fig. 4. The relationship between sucrose equivalents and the composite amount of maltol +3 -furaldehyde +2 -furmethanol formed per clone during baking.

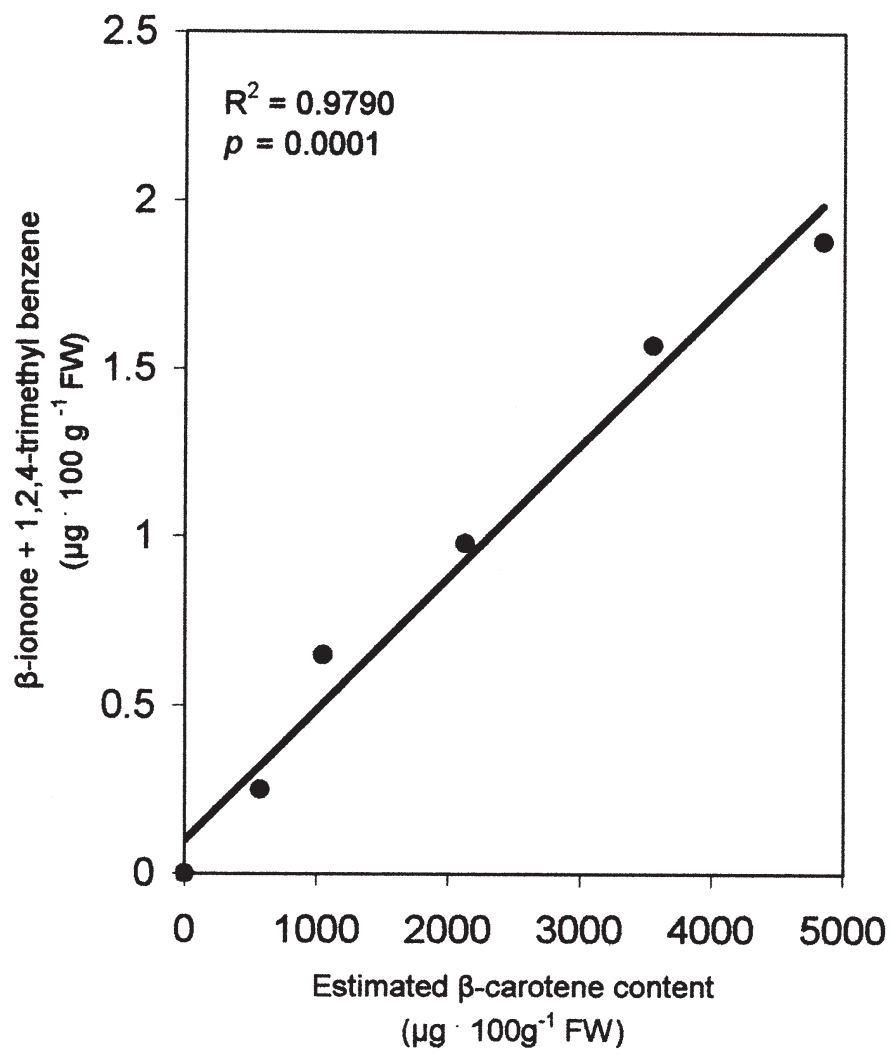

Fiig. 5. The relationship between estimated $\beta$-carotene content and $\beta$-ionone and 1,2,4-trimethyl benzene content during baking for six sweetpotato clones.

among the six clones. The sesquiterpenes may be important contributors to the aroma of GA90-10 in that their concentrations were significantly higher, conferring a strong terpene aroma. The sesquiterpenes $\beta$-farnesene, $\alpha$-bisbolene, and $\beta$-caryophyllene were present in each of the clones but contributed only a very faint terpene odor. A terpene aroma note appears to be pandemic in the sweetpotato genepool (McLaurin and Kays, 1992) but does not always dominate the aroma due to the contributions of other compounds. The terpene biosynthetic pathway appears to be upregulated in many Ipomoea species (Starr et al., 1991).

Phenylacetaldehyde (perfume) and benzaldehyde (almond), important contributors to sweetpotato flavor (Wang and Kays, 2000), are believed to be derived from the amino acid phenylalanine (Scarpellino and Soukup, 1993). With the exception of GA90-10, the clones produced significant amounts of both compounds.

Chemometrics of CRITICAL Flavor COMPounds. The characteristic flavor of a sweetpotato clone is due to the presence or absence of sugars and a delicate balance in aroma compounds. Having established distinct differences in flavor components among clones, we tested if it was possible to accurately predict the sensory assessment of flavor using analytical data. Since individual taste and aroma compounds vary in their relative impact on the overall flavor on an equimolar basis, concentration alone is insufficient for assessing their impact. As a consequence, the contribution of each odor-active volatile to the aromas of each clone was calculated as its concentration weighted by its relative aroma intensity (Table 5). The relative weighting factor of each volatile was equal to the flavor dilution (FD) factor divided by its concentration, the former being established with 'Jewel' (Wang and Kays, 2000). The degree of sweetness of individual clones could be accurately predicted using the summation of concentrations of sucrose, fructose, glucose, and maltose weighted for differences in sweetness (sucrose equivalence). Predicting aroma, however, is much more complex due to the large number of odor-active compounds (e.g., 37 for 'Jewel') (Wang and Kays, 2000) and tremendous range in aromas possible. As a preliminary inquiry into the feasibility of developing an objective aroma evaluation system, multivariate statistical techniques were used to categorize the clones based on their volatile chemistry.

Principal component analysis (PCA) allows reducing the complexity of a system, while attempting to preserve the inherent structure and variance of the original data, by reducing the number of dimensions (Johnson and Wichern, 1998). Thus a data set of n-dimensions can be reduced to two- or three-dimensional space. The orthogonal axes for this space are a linear combination of the individual variables such that the first principal component (PC) retains as much variation as possible and the second $\mathrm{PC}$ retains as much of the remaining variance as possible. Excluding methyl geranate and n-decanal which were found only in trace amounts, the compounds listed in Table 6 were selected for analysis. While the results from ANOVA revealed significant differences among clones for each compound (Table 5), PCA allowed comparing the clones based on their combined volatile chemistry. Three PCs having Eigenvalues greater than 1 were used to model the data (Table 6). The Eigenvalues indicate that PC1 and PC2 contained $73.46 \%$ and $16.75 \%$ of the total sample variation for the 17 odoractive volatiles (Table 6). Figure 6 is a two-dimensional plot that separates the clones based upon the uniqueness of their aroma chemistry. 'Jewel' and 'Centennial' have very similar flavors (Table 1) and while separated from each other, they are clustered in one area. Clones having even more distinct aromas (GA90-10 and GA90-16) are substantially more distinct from the traditional North American flavor types. The factor loadings give an indication of the importance of individual volatiles to each PC (Table 6). For example, PC1 was negatively weighted by the three sesquiter- 
Table 6. Factor loadings, eigenvalues and variance explained by the first three principal components for the odor-active compounds from baked sweetpotatoes.

\begin{tabular}{lccc}
\hline Compound & PC1 & PC2 & PC3 \\
\hline Maltol & 0.78397 & 0.43086 & 0.05480 \\
5-Methyl-2-furfural & 0.75272 & 0.31592 & -0.26111 \\
2-Acetyl furan & 0.73601 & -0.46494 & 0.44130 \\
3-Furaldehyde & 0.86483 & 0.28058 & -0.20448 \\
2-Furmethanol & 0.86811 & 0.46164 & -0.09008 \\
Benzaldehyde & 0.94537 & 0.19083 & 0.15004 \\
Phenylacetaldehyde & 0.84636 & -0.24176 & -0.45896 \\
3-Ionone & 0.89191 & 0.37911 & 0.19531 \\
1,2,4-Trimethyl benzene & 0.95604 & 0.21130 & 0.12863 \\
2-Pentyl furan & 0.74713 & -0.00913 & 0.63616 \\
2,4-Decadienal & 0.25652 & -0.91449 & 0.15643 \\
2,4-Nonadienal & 0.88729 & -0.42066 & -0.04755 \\
Linalool & 0.90331 & 0.23072 & 0.28718 \\
Geraniol & 0.74329 & -0.46259 & 0.22199 \\
Cyperene & -0.92598 & 0.02026 & 0.26955 \\
$\alpha$-Copaene & -0.78759 & 0.38023 & 0.8225 \\
Sesquiterpene (MW204) & -0.87906 & 0.36906 & 0.26735 \\
Eigenvalue & 11.57 & 2.63 & 1.54 \\
Variance explained (\%) & 73.46 & 16.75 & 9.80 \\
\hline
\end{tabular}

penes (cyperene, $\alpha$-copaene, and an unknown). It was positively weighted by the remaining volatiles. Thus GA90-10 (Fig. 6), with a strong terpene odor, had a high content of negatively weighted volatiles. GA90-16 was separated from other clones by PC2 due to the negative weighting of 2-acetyl furan, 2,4-decadienal, 2,4-

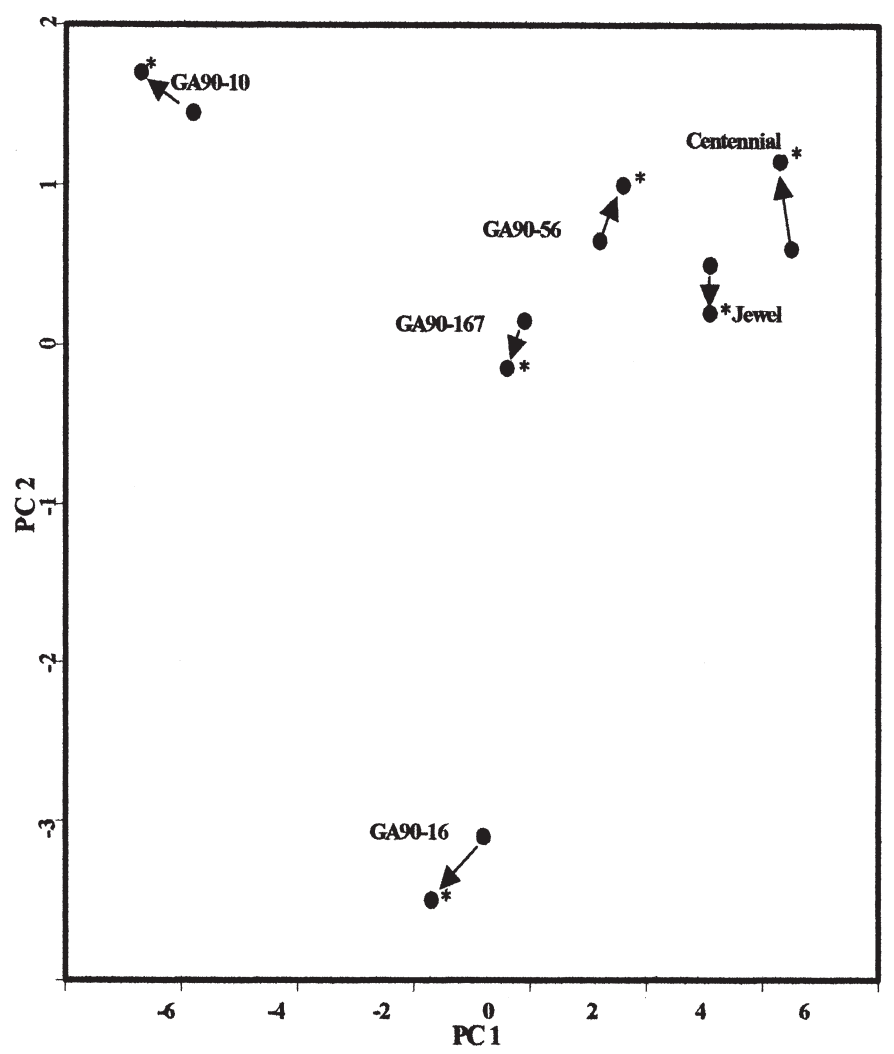

Fig. 6. Principal component analysis (PC1-PC2) using 17 aroma-active volatile compounds in six sweetpotato clones. $(*)=$ the mean point of clone position in PCA based on 17 aroma-active volatiles +4 major sugars; $=$ based on the 17 volatiles) nonadienal, phenylacetaldehyde, and linalool. 2-Acetyl furan and 2,4-decadienal are thought to be the important contributors to the white potato aroma of GA90-16 (Kays et al., 2001). With the exception of 2,4-decadienal (factor loading $=0.25652$ ), all of the variables had high factor loadings (i.e., >0.7) in PC1, indicating that they provide similar and important information to $\mathrm{PC} 1$ for separation. 2,4-Decadienal (-0.91449), however, had the highest absolute loading value to PC2.

To confirm the PCA results and to further assess the differences in aroma among clones, CA was used. A dendrogram based on the 17 aroma-active compounds using the average distance and centroid linkage is shown in Fig. 7. The replications within each clone were clustered and were under 0.1 average distance. No dislocating was found. Therefore, it is possible to classify each clone on the basis of its volatile chemistry. 'Jewel' and 'Centennial' and GA90-56 and GA90-167 were clustered together under 0.3 average distances. The results indicate the similarity in aroma between 'Jewel' and 'Centennial' and between GA90-56 and GA90-167. 'Jewel', 'Centennial', GA90-56, and GA90-167 had an average cluster distance of 0.8 . GA90-16 and GA90-10, in contrast, were much more distinctly different from the other clones having average distances of 1.0 and 1.5. The results reflected quite well the sensory differences in aroma among the clones.

The ability of PCA and CA to separate and cluster clones according to flavor is due to the direct contribution of these odoractive volatiles and sugars to the flavor. Five of the 17 odor-active volatiles used in the PCA and CA were derived from sugars via the Maillard reaction. These volatiles allowed separating and clustering the clones based on their sweetness, e.g., the clones progressed in sweetness diagonally from the $\mathrm{X}-\mathrm{Y}$ intercept from nonsweet to slightly sweet to sweet (Fig. 6). By adding sugar data (sugar concentrations weighted by their relative sweetness) into the PCA and CA, the precision of separating the clones increased. However, there is a trade off between the increased precision and the additional cost (i.e., the requirement for an additional analytical technique for sugar analysis). Alternatively, it is possible to predict the sweetness of a clone fairly precisely using regression analysis of three Maillard reaction volatiles without actually measuring the sugars (Fig. 4).

It is evident from principal component, cluster, and regression analysis that it would be possible to ascertain the general flavor of unknown clones in breeding programs based upon their positioning relative to standard clones for which sensory descriptors have been obtained. Likewise, clones with unique, new flavors would be readily evident. The addition of a wider range in flavor types to the model would enhance the precision of predicting flavor based on flavor chemistry, as would subsets of standards within flavor types. It may also be possible, through further refining of the weighting factors for specific critical volatiles, to additionally increase the precision of predicting flavor.

Flavor analysis via the use of aroma volatiles is a well established method in food science. Since the pioneering work of Powers and Keith (1968) applying discriminate analysis to coffee and peanut aromas, chemometric pattern recognition techniques have progressively improved such that multivariate analysis is routinely used for quality assurance in the food industry (Aishima and Nakai, 1991). For example, pattern recognition analysis has been used for discriminating coffee cultivars (Aishima, 1991; Bicchi et al., 1993) and wines (Etievant et al., 1989; Forina et al., 1986; van der Voet and Doornbos, 1984). We have subsequently improved this technique by including all of the critical flavor compounds (aroma and taste) and weighting each based upon 


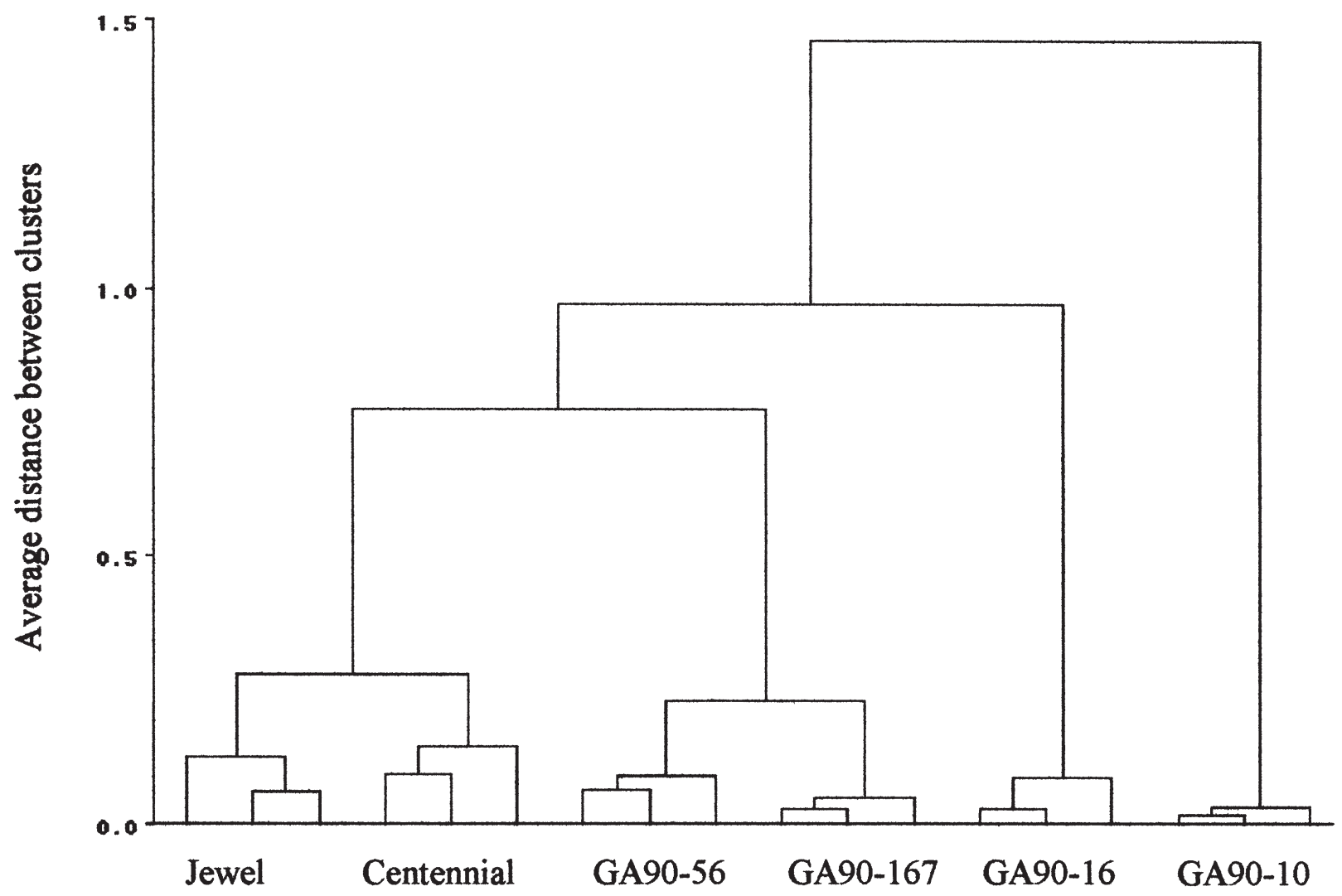

Fig. 7. Dendrogram of a cluster analysis using 17 aroma-active volatile compounds in six sweetpotato clones (triplicate samples of clone).

its relative importance. Our results indicate that pattern recognition analysis using the odor-active volatiles and sugars from sweetpotatoes is an effective means of characterizing the flavor of clones which can be readily automated for the assessment of large numbers of samples.

Using an analytical selection system, the number of clones screened per day can be increased from five to eight using conventional sensory panels to $\approx 40$ to 50 per gas chromatograph. An even more rapid method for quantifying volatile compounds involves the use of solid-phase microextraction (SPME) coupled with time-compressed chromatography (TCC) and time-of-flightmass spectrometry (TOFMS) (Song et al., 1997). The time needed for SPME sampling of apple volatiles was $2 \mathrm{~min}$ and typical TCC/TOFMS analysis times for complex mixtures were 2 to $5 \mathrm{~min}$. As a consequence, $\approx 250$ samples could theoretically be analyzed a day per gas chromatograph.

Incorporation of this technique into a breeding program requires the preferred flavor type of the food crop to be initially determined using conventional sensory groups, followed by characterizing the chemistry of preference. An analytical measurement of aroma and taste for each progeny is then evaluated using pattern recognition analysis against reference standards comprised of a cross-section of flavor types. Since food flavor preference is highly subjective and is known to vary widely among target consumer groups (Shewfelt, 2000), if the flavor preference of multiple populations of consumer groups is known, each progeny from a breeding program can be simultaneously assessed relative to a large number of consumer groups with differing preferences. This allows a single breeding program to accurately select preferred flavor types for anywhere in the world, tremendously increasing the programs efficiency, cost effectiveness, and international impact.
The sweetpotato is an excellent example of the utility of an analytically directed selection system. The widespread prevalence of viral diseases coupled with the fact that the species is asexually propagated makes exchanging germplasm between countries to do conventional sensory analysis a formidable problem. With meristem tip culture, virus-free plants can be produced, however, the process is laborious, time consuming and expensive. As a consequence, it is impractical to meristem-tip culture the large numbers of progeny from a breeding program for subsequent sensory assessment in the country for which the new cultivars are being selected. The ability to initially make flavor selection decisions analytically for foreign consumer populations greatly reduces the number of progeny with desirable flavors to a relatively small number which is manageable via meristem-tip culture.

\section{Conclusions}

Altering the flavor of agricultural food crops via breeding is the primary means of effecting significant improvement, however, the selection of parent clones and superior progeny is the weakest link in the process. The subjective nature of sensory testing and the difficulty of assessing the large numbers of clones, found in typical plant breeding programs, has relegated flavor to one of the last traits assessed (i.e., often determined after $>99 \%$ of the progeny have been discarded). Thus on a numerical basis, the chance of finding superior clones is tremendously reduced.

We described an analytical means of assessing flavor which is amenable to large numbers of lines and allows initial selection decisions to be made without the use of sensory panels. The technique described circumvents two critical deficits in selection for improved flavor quality in plant breeding programs. It greatly increases the accuracy and reproducibility of flavor assessment and it tremendously increases the number of progeny that can 
be assessed. Our data indicate that it is possible to determine the general flavor using aroma and taste chemistry, a process which we have standardized and automated for large numbers of samples. The method is sufficiently precise that in addition to the general flavor, it is possible to predict the concentration of certain internal components ( $\beta$-carotene, sugars, sweetness) by monitoring the concentration of selected aroma volatiles. Further refinement of the technique and expansion of the diversity of the data set in the model should further increase the precision and applied utility of this approach for improving flavor quality via plant breeding.

\section{Literature Cited}

Aishima, T. 1991. Aroma discrimination by pattern recognition analysis of responses from semiconductor gas sensory array. J. Agr. Food Chem. 39:752-756.

Aishima, T. and S. Nakai. 1991. Chemometrics in flavor research. Food Rev. Intl. 7:33-101.

Bicchi, C.P., A.E. Binello, M.M. Legovich, G.M. Pellelgrino, and A.C. Vanni. 1993. Characterization of roasted coffee by S-HSGC and HPLC-UV and principal component analysis. J. Agr. Food Chem. 41:2324-2328.

Buttery, R.G., D.G. Guadagni, and L.C. Ling. 1973. Volatile compounds of baked potatoes. J. Agr. Food Chem. 24:1125-1131.

Chapman, G.W. and R.J. Horvat. 1989. Determination of nonvolatile acids and sugars of fruits and sweetpotato extracts by capillary GLC and GLC/MS. J. Agr. Food Chem. 37:947-950.

Edmond, J.B. and C.R. Ammerman. 1971. Sweet potatoes: Production, processing, marketing. AVI, Westport, Conn.

Etievant, P., P. Schlich, R. Cantgrel, A. Bertrand, and J.-C. Bouvier. 1989. Varietal and geographic classification of French red wines in terms of major acids. J. Sci. Food Agr. 46:421-438.

Food and Agriculture Organization. 1997. FAO production yearbook. vol. 51. FAO, United Nations, Rome.

Forina, M., C. Armonino, M. Castino, and M. Ubigli. 1986. Multivariate data analysis as a discriminating method of the origin of wines. Vitis 25:189-201.

Grosch, W. 1993. Detection of potent odorants in foods by aroma extract dilution analysis. Trends Food Sci. Technol. 4:68-73.

Grosch, W. and P. Schieberle. 1997. Flavor of cereal products-Areview. Cereal Chem. 74:91-97.

Johnson, R.A. and D.W. Wichern. 1998. Applied multivariate statistical analysis. Prentice Hall, Upper Saddle River, N.J.

Kanasawud, P. and C. Crouzet. 1990. Mechanism of formation of volatile compounds by thermal-degradation of carotenoids in aqueous medium. 1. $\beta$-Carotene degradation. J. Agr. Food Chem. 38:237-243.

Kays, S.J. 1985. Formulated sweet potato products, p. 205-218. In: J. Bouwkamp (ed.). Sweet potato products: A natural resource of the tropics. CRC Press, Boca Raton, Fla.

Kays, S.J. and S.E. Kays. 1998. Sweetpotato chemistry in relation to health, p. 221-272. In: D.R. LaBonte and H. Mochida (eds.). Sweetpotato production system toward the 21th century. Kyushu Natl. Agr. Expt. Sta., Miyazaki, Japan.

Kays, S.J. and Y. Wang. 2000. Thermally induced flavor compounds. HortScience 35:1002-1012.

Koehler, P.E. and S.J. Kays. 1991. Sweetpotato flavor-quantitative and qualitative assessment of optimum sweetness. J. Food Quality.14: 241-249.

Law, J.M. 1977. Factors affecting purchase and use of sweet potatoes. La. State Univ. Agr. Expt. Sta. Bul. 706:5-36.

Lewthwaite, S.L., K.H. Sutton, and C.M. Triggs. 1997. Free sugar composition of sweetpotato cultivars after storage. N.Z. J. Crop Hort. Sci. 25:33-41.

McLaurin, W.J. and S.J. Kays. 1992. Genetic diversity in sweetpotato flavor, p. 420-427. In: W.A. Hill, C.K. Bonsi, and P.A. Loretan (eds.).
The sweetpotato in the 21th century. 2nd Intl. Symp. Sweetpotatoes, Tuskegee Univ., Tuskegee, Ala.

Morrison, T.A., R. Pressey, and S.J. Kays. 1993. Changes in $\alpha$-amylase and $\beta$-amylase during storage of sweetpotato lines with varying starch hydrolysis potential. J. Amer. Soc. Hort. Sci. 118:236-242.

Picha, D.H. 1985. HPLC determination of sugars in raw and baked sweetpotatoes. J. Food Sci. 50:1189-1190.

Picha, D.H. 1986. Influence of storage duration and temperature on sweet potato sugar content and chip color. J. Food Sci. 51:239-240.

Powers J.J. and E.S. Keith. 1968. Stepwise discriminate analysis of gas chromatographic data as an aid in classifying flavor quality of foods. J. Food. Sci. 33:207-213.

Scarpellino, R. and R.J. Soukup. 1993. Key flavors from heat reaction of food ingredients, p. 309-333. In: T.E. Acree and R. Teranishi (eds.). Flavor science, sensible principles and techniques. Amer. Chem. Soc., Wash., D.C.

Shallenberger, R.S. 1993. Taste chemistry. Blackie Acad. \& Prof. New York. p. 193-194.

Shewfelt, R.L. 2000. Consumer friendly specifications for a global marketplace. Food Austral. 52:311-314.

Simonne, A.H., S.J. Kays, P.E. Koehler, and R.R. Eitenmiller. 1993. Assessment of $\beta$-carotene content in sweetpotato breeding lines in relation to dietary requirements. J. Food Composition Anal. 6:336-345.

Song, J., B.D. Gardner, J.F. Holland, and R.M. Beaudry. 1997. Rapid analysis of volatile flavor compounds in apple fruit using SPME and GC/Timeof-flight mass spectrometry. J. Agr. Food Chem. 45:1801-1807.

Starr, C.K., R.F. Severson, and S.J. Kays. 1991. Volatile chemicals from sweetpotato and other Ipomoea: Effects on the behavior of Cylas formicarious, p. 235-246. In: R.K. Jansson and K.V. Raman (eds.). Sweetpotato pest management, Westview Press, Boulder, Colo.

Sun, J.S., R.F. Severson, and S.J. Kays. 1993. Quantitative technique for measurement of the volatile components of baked sweetpotatoes. HortScience 28:1110-1113.

Sun, J.S., R.F. Severson, and S.J. Kays. 1994. Effect of heating temperature and microwave pretreatment on the formation of sugar and volatiles in 'Jewel' sweetpotato. J. Food Qual. 17:447-456.

Sun, J.S., R.F. Severson, and S.J. Kays. 1995. Identifying critical volatiles in the flavor of baked 'Jewel' sweetpotatoes [Ipomoea batatas (L.) Lam.]. J. Amer. Soc. Hort. Sci. 120:468-474.

Takahata, Y., T. Noda, and T. Nagata. 1992. Varietal diversity of free sugar composition in storage roots of sweetpotatoes. Jpn. J. Breeding 42:515-521.

Tiu, C.S., A.E. Purcell, and W.W. Collins. 1985. Contribution of some volatile compounds to sweetpotato aroma. J. Agr. Food Chem. 33: 223-226.

van der Voet, H. and D.A. Doornbos. 1984. The use of pattern recognition techniques in chemical differentiation between Bordeaux and Bourgogne wines. Anal. Chem. Acta 159:159-171.

Villareal, R.L. 1982. Sweet potato in the tropics-progress and problems, p. 1-15. In: R.L. Villareal and T.D. Griggs (eds.). Proc. $1^{\text {st }}$ Intl. Symp. Sweetpotato. Asian Veg. Res. Dev. Ctr., Shanhua, Taiwan.

Villareal, R.L., S.C. Tsou, S.H. Lai, and S.L. Chiu. 1979. Selection criteria for eating quality in steamed sweetpotato roots. J. Amer. Soc. Hort. Sci. 104:31-33.

Walter, Jr., W.M., A.E. Purcell, and M.W. Hoover. 1976. Changes in amyloid carbohydrates during preparation of sweetpotato flakes. J. Food Sci. 41:1374-1377.

Walter, Jr., W.M.,A.E. Purcell, and A.M. Nelson. 1975. Effects of amyloid enzymes on moistness and carbohydrate changes of baked sweetpotato cultivars. J. Food Sci. 40:793-796.

Wang, Y. and S.J. Kays. 2000. Contribution of volatile compounds to the characteristic aroma of baked 'Jewel' sweetpotatoes. J. Amer. Soc. Hort. Sci. 125:638-643.

Wang, Y. and S.J. Kays. 2001. Effect of cooking method on the aroma constituents of sweetpotatoes [Ipomoea batatas (L.) Lam.]. J. Food Quality. 24:67-78.

Woolfe, J.A. 1992. Sweetpotato. Cambridge Univ. Press, Cambridge, U.K. 